\title{
Administration of ghrelin associated with decreased expression of matrix metalloproteinase-9 following normobaric systemic hypoxia in the brain
}

\author{
Gisou Mohaddes ${ }^{1}$, Shirin Babri ${ }^{1}$, Fezzeh Hossienzadeh ${ }^{1,2}$ \\ ${ }^{1}$ Neuroscience Research Center of Tabriz University of Medical Sciences, Tabriz, Iran; ${ }^{2}$ Faculty of Medical Sciences, \\ Sarab, Tabriz University of Medical Sciences, Tabriz, Iran \\ E-mail: Hossenzadeh_Fez@yahoo.com
}

\begin{abstract}
Objective. According to our previous studies, ghrelin protects blood brain barrier (BBB) integrity and it attenuates hypoxia-induced brain edema in the hypoxic conditions. However, the underlying mechanisms remain poorly understood. Several studies suggest a role for matrix metalloproteinase-9 (MMP9) in the BBB disruption and cerebral edema formation. The present study was conducted to determine the effect of ghrelin on MMP9 protein expression in the model of acute and chronic systemic hypoxia.

Methods. Adult male Wistar rats were divided into acute or chronic controls, acute or chronic hypoxia and ghrelin-treated acute or chronic hypoxia groups. The hypoxic groups were kept in the hypoxic chamber $\left(10-11 \% \mathrm{O}_{2}\right)$ for two (acute) or ten days (chronic). Effect of ghrelin on MMP9 protein expression was assessed using immunoblotting.

Results. Our results showed that acute and chronic systemic hypoxia increased the MMP9 protein expression in the brain $(\mathrm{p}<0.001)$. Treatment with ghrelin significantly attenuated this expression in the cerebral hypoxia $(\mathrm{p}<0.05)$.

Conclusion. Our results demonstrate that the neuroprotective effects of ghrelin may be mediated, in part, by decreasing in MMP9 production in the hypoxic brain.
\end{abstract}

Key words: hypoxic brain, matrix metalloproteinase-9, ghrelin

Ghrelin, a 28 amino acid peptide hormone, is mainly secreted by the fundus of the stomach and is an endogenous ligand for growth hormone secretagogue receptor la (Kojima et al. 1999). The ghrelin receptors are expressed in different regions of the central nervous system (CNS), for example cerebral cortex, hypothalamus or blood vessels (Zigman et al. 2006; Chung et al. 2007; Lee et al. 2014). The pattern of its receptors distribution in the CNS indicates different functions for ghrelin such are the regulation energy balance, food intake, control of behavior, memory performance (Carlini et al. 2002; Diano et al. 2006; Fry and Ferguson 2010; Babri et al. 2013) etc. Moreover, several experimental studies have shown that ghrelin, as an anti-inflammation, neuroprotection and anti-apoptosis agent, reduces cerebral injuries in animal models (Brywe et al. 2005; Liu et al. 2006; Miao et al. 2007; Chung et al. 2008; Andrews 2011). In addition, in previous studies, we and others have shown that ghrelin treatment ameliorates blood brain barrier (BBB) disruption and attenuates cerebral edema, in which ghrelin acts via decrease of the inflammatory cytokines expression such as TNF- $\alpha$, interleukin (IL)-1 $\beta$, IL- 6 and vascular endothelial growth factor (VEGF) and it also inhibits the degradation of tight junction proteins such as zonula occludens-1( ZO-1) and occludin in several experimental models including subarachnoid hemorrhage,

Corresponding author: Fezzeh Hossienzadeh, Faculty of Medical Sciences, Sarab, Tabriz University of Medical Science, Tabriz, Iran; phone/fax: +98-41-43237981; e-mail: Hossenzadeh_Fez@yahoo.com. 
traumatic brain injury, and systemic hypoxia (Bansal et al. 2010; Ersahin et al. 2010; Hossienzadeh et al. 2013; Mohaddes et al. 2015, 2017).

There are also evidences that ghrelin reduces myeloperoxidase activity, neutrophil trafficking, nitric oxide synthase (nNOS), as well as matrix metalloproteinase-9 (MMP9) in spinal cord injury and middle cerebral artery occlusion (MCAO) models (Cheyuo et al. 2011; Zhang et al. 2012).

Huang et al. (2009) have indicated in their research that ghrelin has a protective effect against myocardial infarction in rats, through reducing MMP9 expression. Recently, it has been reported that administration of ghrelin immediately after spinal cord injury (SCI) considerably protects the disruption of the blood spinal cord barrier (BSCB) and hemorrhage via down-regulation MMP9 (Lee et al. 2014).

The MMP9 is a member of the MMPs family (Sato et al. 1996) that is expressed in brain at relatively low levels under physiologic conditions (Cunningham et al. 2005). However, MMP-9 expression increased in a very large number of brain pathologies, including cerebral ischemia, traumatic brain injury, and hypoxic brain that cause BBB disruption and cytotoxic and vasogenic brain edema formation (Yang et al. 2007; Rosenberg 2009; Bauer et al. 2010; Duran-Vilaregut et al. 2011; Higashida et al. 2011).

To our knowledge, only a few reports have shown the effects of ghrelin on MMP9 protein following experimental cerebral damages and no study, to date, has reported its effects in hypoxic brain. Therefore, the present study aimed to evaluate the effect of ghrelin on MMP9 protein levels in the hypoxic brain that was induced by systemic acute and chronic hypoxia in the rats.

\section{Materials and methods}

Animals and experimental groups. Adult male Wistar rats $(235 \pm 15 \mathrm{~g})$ were purchased from the Tabriz University of Medical Sciences and housed in standard cages in a temperature $\left(22-24^{\circ} \mathrm{C}\right)$, humidity (40-60\%), and light period (12-h light/dark cycle) controlled environment. Food and water were available ad libitum. Experiments were performed in conformity with the Care and Use of Laboratory Animals (National Institutes of Health Publication No. 85-23 revised 1985) and were approved by the research and ethics committee of the Tabriz University of Medical Sciences(No: 89/4-13/11).

The rats $(n=36)$ were randomly divided into six groups $(n=6)$, including acute or chronic control groups, acute or chronic hypoxia and ghrelin-treated acute or chronic hypoxia groups. Control and hypoxic (acute and chronic) groups received saline $(1 \mathrm{ml} / \mathrm{kg}$, i.p., daily). Ghrelin-treated acute and chronic hypoxic groups received acylated ghrelin (Innovagen, Sweden) at a dose of $80 \mu \mathrm{g} / \mathrm{kg}$, i.p., daily for 2 or 10 days, respectively (Hossienzadeh et al. 2013).

Induction of acute and chronic systemic hypoxia. Control groups were kept in room air $\left(21 \% \mathrm{O}_{2}\right)$. Acute and chronic systemic hypoxia $\left(10-11 \% \mathrm{O}_{2}\right)$ were induced in the hypoxic chamber (GO2 AltitudeBiomedical, Australia). Acute and chronic hypoxic groups were kept in the chamber all the time for 2 and 10 days, respectively; except for cleaning the cages and daily injections.

Western blot analysis. For studying western blot, the rats were sacrificed after anesthetizing by an overdose of sodium pentobarbital $(100 \mathrm{mg} / \mathrm{kg})$, the brains immediately were removed and frozen in liquid nitrogen. Then, the brain samples were homogenized as described previously (Mohaddes et al. 2015). Equal amounts of samples ( $20 \mu \mathrm{g}$ protein) were electrophoretically separated on $10 \%$ SDS-PAGE gels. The lysates were transferred to polyvinylidene difluoride (PVDF) membranes, blocked with 5\% milk and incubated 90 min or $1 \mathrm{~h}$ at room temperature with primary antibodies against MMP9 (Abcam, Cat \# ab76003) and beta actin (Abcam, Cat \# 8227), diluted 1:1000 and 1:5000 in blocking solution, respectively. Followed by washing, incubation with an HRP-conjugated secondary antibody diluted 1:3000 in 5\% milk/PBS-T for $1 \mathrm{~h}$ at room temperature and more washing; the blots were imagined with the enhanced chemiluminescence (ECL) detection kit for $1 \mathrm{~min}$ and then exposed to hyper film for $60 \mathrm{~s}$ to $10 \mathrm{~min}$. Finally, the films were scanned, and the density of the immunoreactive bands was determined by Image J software and normalized to the bands of the internal control (beta-actin).

Statistical analysis. Data are presented as mean \pm SD. Differences in the image density were compared by Nonparametric Kruskal-Wallis test followed by Mann-Whitney test. A p value less than $0.05(p<0.05)$ was considered statistically significant. SPSS 17.0 software was used for statistical comparisons of data.

\section{Results}

Effects of acute systemic hypoxia and ghrelin treatment on MMP9 protein level in the hypoxic brain. Western blot analysis showed that acute hypoxia significantly increased the MMP9 protein level compared with the acute control group $(2.49 \pm 0.16$ 
vs. $1.0 \pm 0.0, \mathrm{p}<0.001)$ and ghrelin administration significantly attenuated the MMP9 protein expression in the acute hypoxic group $(1.85 \pm 0.36$ vs. $2.49 \pm 0.16$, $\mathrm{p}<0.05)$. In addition, ghrelin treatment did not significantly change the MMP9 protein expression in comparison with the acute control group $(1.85 \pm 0.36$ vs. $1.0 \pm 0.0, \mathrm{p}>0.05$ ) (Figure 1 ).

Effects of chronic systemic hypoxia and administration of ghrelin on MMP9 protein level in the hypoxic brain. Western blot analysis showed that chronic hypoxia significantly increased the MMP9 protein expression in comparison with the chronic control group $(1.3 \pm 0.15$ vs. $1.0 \pm 0.0, \mathrm{p}<0.001)$, and ghrelin injection significantly decreased the MMP9 protein expression in comparison with the chronic

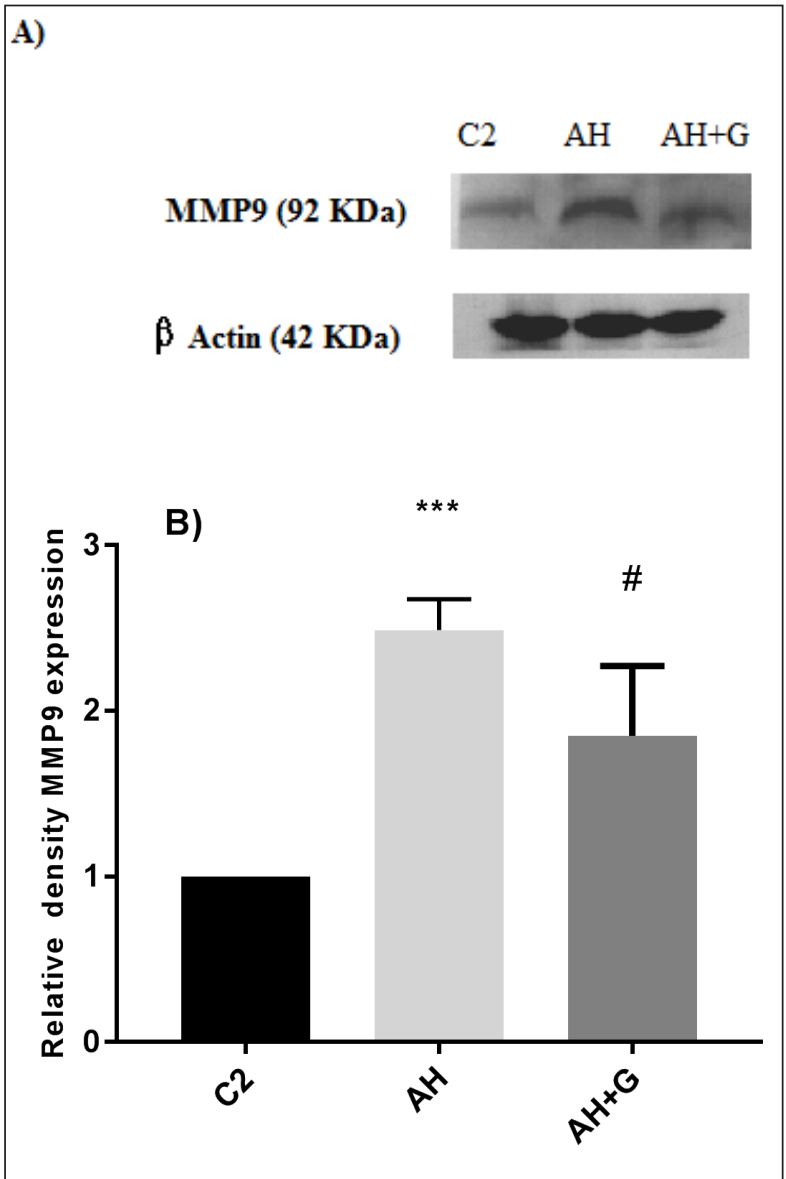

Figure 1. A) Western blots showed an increase in the MMP9 expression in the acute hypoxic group (lane 2). Ghrelin administration reduced the MMP9 expression in comparison with acute hypoxic group (lane 3). B) The MMP9 expression in acute control (C2) and acute hypoxic ( $\mathrm{AH}$ ) groups that received saline or ghrelin $(\mathrm{AH}+\mathrm{G})$ for two days. Data are expressed as mean \pm SD for 6 animals per group. ${ }^{* * *} p<0.001$ versus the control group; ${ }^{*} \mathrm{p}<0.05$ versus the $\mathrm{AH}$ group. hypoxic group $(0.84 \pm 0.33$ vs. $1.3 \pm 0.15, \mathrm{p}<0.05)$. In addition, treatment with ghrelin did not significantly change the MMP9 protein expression in comparison with the chronic control group $(0.84 \pm 0.33$ vs. $1.0 \pm 0.0$, $\mathrm{p}>0.05$ ) (Figure 2).

Effects of acute and chronic systemic hypoxia and ghrelin administration on MMP9 protein level in the hypoxic brain. The acute and chronic systemic hypoxia significantly increased the MMP9 protein expression in comparison with the acute and the chronic control groups $(\mathrm{p}<0.001)$. Administration of ghrelin significantly decreased the expression of MMP9 in both the acute and chronic hypoxic groups $(\mathrm{p}<0.05)$. In addition, the MMP9 expression was significantly different between the acute hypoxic (AH)

A

\section{$\mathrm{C} 10 \quad \mathrm{CH} \quad \mathrm{CH}+\mathrm{G}$}

MMP9 (92 KDa)

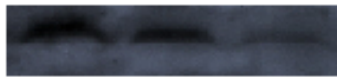

$\beta$ Actin (42 KDa)
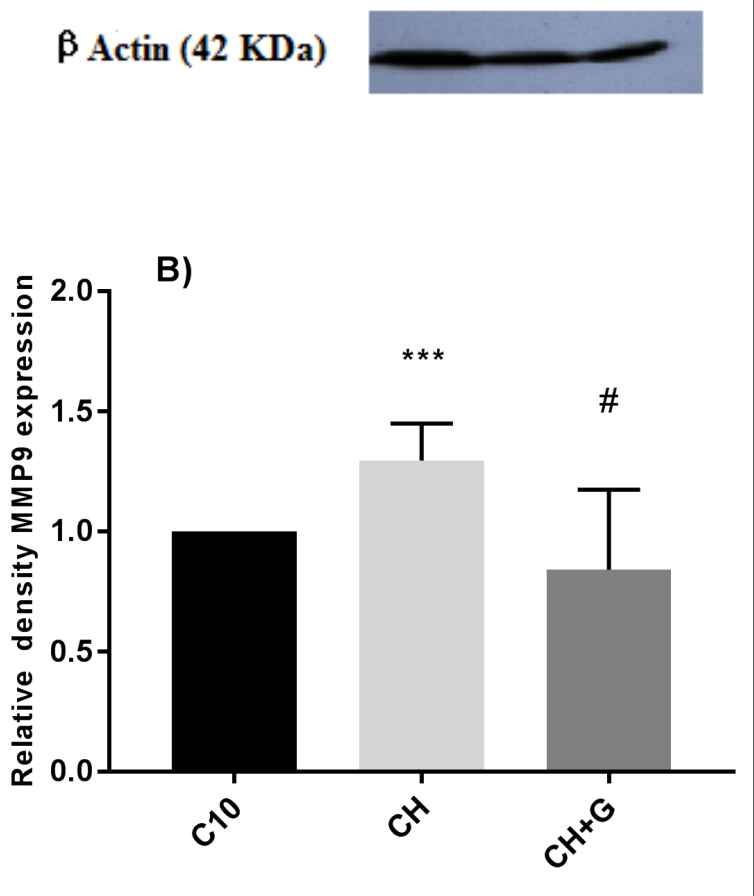

Figure 2. A) Western blots showed an increase in the MMP9 expression in the chronic hypoxic group (lane 2). Ghrelin decreased the MMP9 expression in comparison with chronic hypoxic group (lane 3). B) The MMP9 expression in the chronic control $(\mathrm{C} 10)$ and chronic hypoxic $(\mathrm{CH})$ group that received saline or ghrelin $(\mathrm{CH}+\mathrm{G})$ for 10 days. Data are expressed as mean \pm SD for 6 animals per group. ${ }^{* *} \mathrm{p}<0.001$ versus the Control group and ${ }^{*} \mathrm{p}<0.05$ versus the $\mathrm{CH}$ group. 
and the chronic hypoxic $(\mathrm{CH})$ groups $(\mathrm{p}<0.001)$. Also, the MMP9 expression significantly changed between the ghrelin-treated acute hypoxic group $(\mathrm{AH}+\mathrm{G})$ and the ghrelin-treated chronic hypoxic group $(\mathrm{CH}+\mathrm{G})$ $(\mathrm{p}<0.001)$. The expression of MMP9 did not change in both the acute and chronic control groups ( $\mathrm{p}>0.05)$ (Figure 3).

\section{Discussion}

Our previous studies have shown that treatment of ghrelin attenuates hypoxia-induced brain edema along with decreasing TNF- $\alpha$ and VEGF proteins levels and it also inhibits the degradation of tight junction proteins such as ZO-1 and occludin in the hypoxic brain (Hossienzadeh et al. 2013; Mohaddes et al. 2015, 2017). But, the neuroprotective effects mechanisms of ghrelin are not completely clear in the hypoxic conditions. Therefore, in the present study we investigated the effect of ghrelin on MMP9 protein level in the hypoxic brain. Results of the present study showed that systemic administration of ghrelin significantly reduces MMP9 protein level in the hypoxic brain following acute and chronic systemic hypoxia.

Our results are in accordance with recent work showing a neuroprotective effect of ghrelin on blood spinal cord barrier disruption, by down-regulating
MMP9 following traumatic spinal cord injury in rats (Lee et al. 2014). Furthermore, our results are consistent with other study showing a decreased production in MMP9 protein level following treatment of ghrelin in myocardial infarction in rats (Huang et al. 2009).

There are evidences that in the central nervous system, more activation and MMP9 protein expression play a key role in the degradation of the extracellular matrix, tight junction proteins inducing vascular permeability in the ischemic, hypoxic brain, and traumatic spinal cord injury models (Yang et al. 2007; Rosenberg 2009; Bauer et al. 2010; Duran-Vilaregut et al. 2011; Higashida et al. 2011). Several studies have shown that inhibition of MMP-9 protein expression and its activation significantly decreases blood brain barrier damage, brain vessels leakage, and infarct size in several animal models (Wang et al. 2000; Asahi et al. 2001; Gasche et al. 2001).

Underlying mechanisms of ghrelin on activation and the MMP9 protein expression have not been elicited yet. Several studies have demonstrated that the inflammatory cytokines such as TNF- $\alpha$ and excess free radicals increase expression and activation of MMP9 (Vecil et al. 2000; Bond et al. 2001; Duansak and Schmid-Schonbein 2013). Several studies have also reported that MMP9 activity is associated with VEGF release (Belotti et al. 2003; Reszec et al. 2015). Furthermore, according to a study by Wang

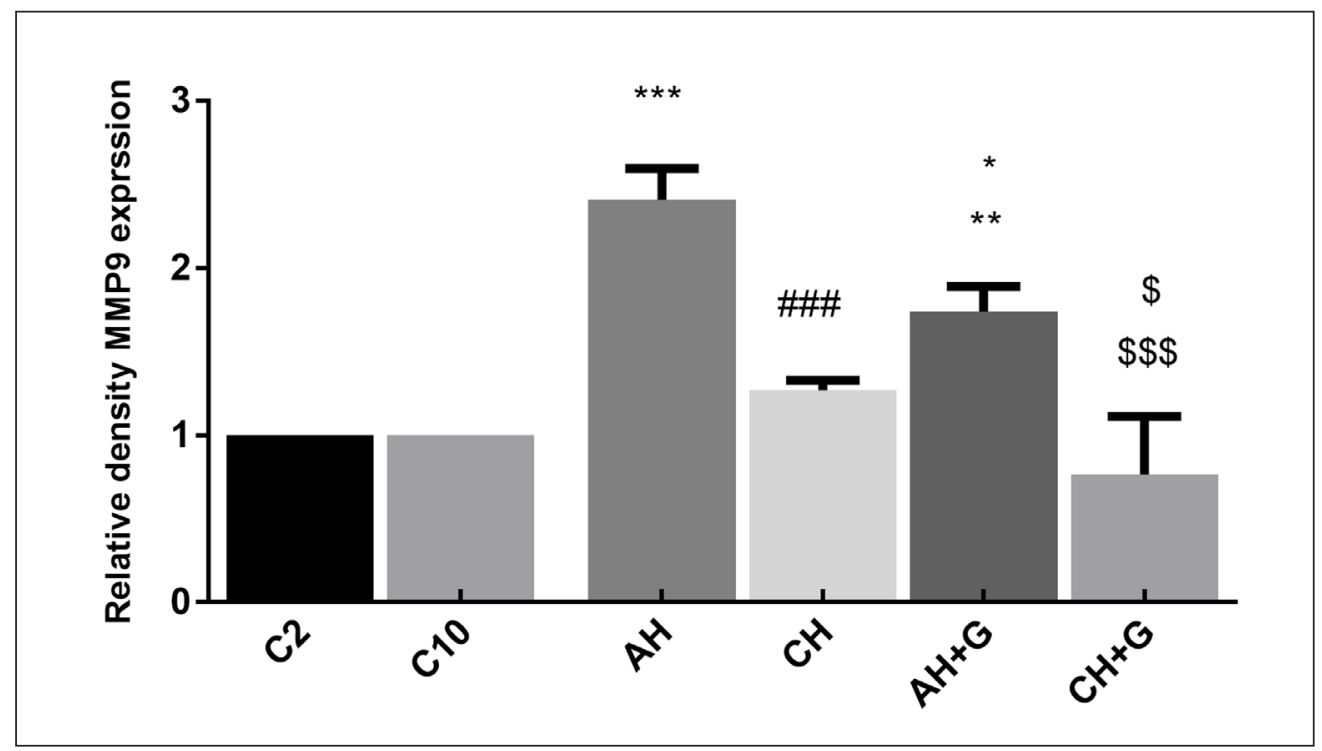

Figures 3. The MMP9 protein expression in the acute control (C2) and the chronic control (C10), the acute hypoxic $(\mathrm{AH})$ and the chronic hypoxic $(\mathrm{CH})$ groups and hypoxic groups that received ghrelin for 2 days $(\mathrm{AH}+\mathrm{G})$ or for 10 days $(\mathrm{CH}+\mathrm{G})$. Data are expressed as mean \pm SD for 6 animals per group. ${ }^{* * *} \mathrm{p}<0.001$ versus the $\mathrm{C} 2$ and the $\mathrm{C} 10$ groups; ${ }^{* \# *} \mathrm{p}<0.001$ versus $\mathrm{AH}$ group; ${ }^{*} \mathrm{p}<0.05$ versus the $\mathrm{AH}$ group; ${ }^{\$} \mathrm{p}<0.05$ versus the $\mathrm{CH}$ group; ${ }^{\$ \$ \$} \mathrm{p}<0.001$ versus $\mathrm{AH}+\mathrm{G}$ group. 
and Keiser (1998), VEGF stimulates the secretion of MMPs from vascular smooth muscle cell (SMC). Since our previous studies have shown that ghrelin decreases synthesis of TNF- $\alpha$ and VEGF protein levels (Hossienzadeh et al. 2013; Mohaddes et al. 2015) and it also has an antioxidant and free radical scavenger activities in the hypoxic brain (Kheradmand et al. 2010). It is more probably that the effect of ghrelin on MMP9 protein expression might be related to its inhibitory effects on TNF- $\alpha$, VEGF levels as well as antioxidant activity in the hypoxic condition. Furthermore, our recent study has reported that treatment of ghrelin inhibits degradation ZO-1 and occludin, tight junction proteins, in the hypoxic brain. In fact, the anti-edematous effect of ghrelin observed in our previous study is likely related to, at least in part, the inhibition of the production of MMP9 protein and its activity in the hypoxic brain. Although, in the present study the effect ghrelin on MMP9 activation was not determined, others studies have revealed that ghrelin treatment attenuates MMP9 activation (Huang et al. 2009; Lee et al. 2014).

In addition, it was shown that chronic hypoxia significantly increases the erythropoietin (EPO) plasma level in rats but ghrelin treatment decreases both plas$\mathrm{ma} \mathrm{EPO}$ and $\mathrm{EPO}$ gene expression in the hypoxic rats (Feizi et al. 2014). On the other hand, EPO inhibited expression of TNF- $\alpha$ and MMP9 during ischemiareperfusion injury (Wu et al. 2009) as well as pro-inflammatory cytokines in rodent brains during oxygen toxicity (Sifringer et al. 2009). Besides, the EPO regulates vascular smooth muscle cells proliferation and migration (Park et al. 2015). Although in the present study, we did not measure plasma EPO level and gene expression, Feizi et al. (2014) have shown that ghrelin administration decreases both plasma EPO levels and gene expression in the chronic hypoxic condition. It seems that our present finding is in disagreement with studies showing effects of the EPO on decreasing expression of TNF- $\alpha$ and MMP9 as well as proinflammatory cytokines in the several animal models (Sifringer et al. 2009; Wu et al. 2009). Although the reason for this discrepancy is not clear, it may be related to the experimental design, methodology or differences in the underlying mechanisms of the EPO during ischemia-reperfusion injury and oxygen toxicity versus the acute and chronic systemic hypoxia.

Therefore, we suggest that decrease of the MMP9 protein level and its activation following ghrelin injection is more likely done through the decreasing inflammatory factors, their signaling pathways, and free radicals as well as VEGF protein consequently, the protection of the BBB against damage in during systemic hypoxia. More studies are needed to elucidating these possibilities. In conclusion, we propose that the neuroprotective effects of ghrelin, in part, must be mediated by decreasing the MMP9 production in the hypoxic brain. Moreover, ghrelin may be a new therapeutic strategy for the treatment of hypoxia-induced brain edema.

\section{Acknowledgments}

This study was supported by the Neuroscience Research Centre of Tabriz University of Medical Sciences, grant number 7-60-89. The authors would like to thank also to Mr. Mahmod Reza Hassanzadeh for his helpful assistance in the laboratory.

\section{References}

Andrews ZB. The extra-hypothalamic actions of ghrelin on neuronal function. Trends Neurosci 34, 31-40, 2011.

Asahi M, Wang X, Mori T, Sumii T, Jung JC, Moskowitz MA, Fini ME, Lo EH. Effects of matrix metalloproteinase-9 gene knock-out on the proteolysis of blood-brain barrier and white matter components after cerebral ischemia. J Neurosci 21, 7724-7732, 2001.

Babri S, Mohaddes G, Alipour MR, Ebrahimi H, Hossenzadeh F. Effects of ghrelin on plasma glucose levels, body weight, food intake and hematocrit in acute and chronic systemic hypoxia in adult male rats. Iran J Endocrinol Metab 15, 100-106, 2013.

Bansal V. Ryu SY, Blow C, Costantini T, Loomis W, Elicerri B, Baird A, Wolf P, Coimbra R. The hormone ghrelin prevents traumatic brain injury induced intestinal dysfunction. J Neurotrauma 27, 2255-2260, 2010.

Bauer AT, Burgers HF, Rabie T, Marti HH. Matrix metalloproteinase-9 mediates hypoxia-induced vascular leakage in the brain via tight junction rearrangement. J Cereb Blood Flow Metab 30, 837-848, 2010.

Belotti D, Paganoni P, Manenti L, Garofalo A, Marchini S, Taraboletti G, Giavazzi R. Matrix metalloproteinases (MMP9 and MMP2) induce the release of vascular endothelial growth factor (VEGF) by ovarian carcinoma cells: implications for ascites formation. Cancer Res 63, 5224-5229, 2003.

Bond M, Chase A, Baker AH, Newby AC. Inhibition of transcription factor NF- $\kappa$ B reduces matrix metalloproteinase-1, -3 and -9 production by vascular smooth muscle cells. Cardiovasc Res 50, 556-565, 2001. 
Brywe KG, Leverin AL, Gustavsson M, Mallard C, Granata R, Destefanis S, Volante M, Hagberg H, Ghigo E, Isgaard J. Growth hormone-releasing peptide hexarelin reduces neonatal brain injury and alters Akt/glycogen synthase kinase-3 beta phosphorylation. Endocrinology 146, 4665-4672, 2005.

Carlini VP, Monzon ME, Varas MM, Cragnolini AB, Schioth HB, Scimonelli TN, de Barioglio SR. Ghrelin increases anxiety-like behavior and memory retention in rats. Biochem Biophys Res Commun 299, 739-743, 2002.

Cheyuo C, Wu R, Zhou M, Jacob A, Coppa G, Wang P. Ghrelin suppresses inflammation and neuronal nitric oxide synthase in focal cerebral ischemia via the vagus nerve. Shock 35, 258-265, 2011.

Chung H, Kim E, Lee DH, Seo S, Ju S, Lee D, Kim H, Park S. Ghrelin inhibits apoptosis in hypothalamic neuronal cells during oxygen-glucose deprivation. Endocrinology 148, 148-159, 2007.

Chung H, Seo S, Moon M, Park S. Phosphatidylinositol-3 kinase/Akt/glycogen synthase kinase-3 beta and ERK1/2 pathways mediate protective effects of acylated and unacylated ghrelin against oxygen-glucose deprivationinduced apoptosis in primary rat cortical neuronal cells. J Endocrinol 198, 511-521, 2008.

Cunningham LA, Wetzel M, Rosenberg GA. Multiple roles for MMPs and TIMPs in cerebral ischemia. Glia 50, 329-339, 2005.

Diano S, Farr SS, Benoit SC, McNay EC, Silva I, Horvath B, Gaskin FS, Nonaka N, Jaeger LB, Banks MA, Morley JE, Pinto S, Sherwin RS, Xu L, Yamada KA, Sleeman MW, Tschop MH, Horvath TL. Ghrelin controls hippocampal spine synapse density and memory performance. Nat Neurosci 9, 381-388, 2006.

Duansak N, Schmid-Schonbein GW. The oxygen free radicals control MMP-9 and transcription factors expression in the spontaneously hypertensive rat. Microvasc Res 90, 154-161, 2013.

Duran-Vilaregut J, del Valle J, Manich G, Camins A, Pallas M, Vilaplana J, Pelegri C. Role of matrix metalloproteinase-9 (MMP-9) in striatal blood-brain barrier disruption in a 3-nitropropionic acid model of Huntington's disease. Neuropathol Appl Neurobiol 37, 525-537, 2011.

Ersahin M, Toklu HZ, Erzik C, Cetinel S, Akakin D, Velioglu-Ogunc A, Tetik S, Ozdemir ZN, Sener G, Yegen BC. The antiinflammatory and neuroprotective effects of ghrelin in subarachnoid hemorrhage-induced oxidative brain damage in rats. J Neurotrauma 27, 1143-1155, 2010.

Feizi H, Rajaee K, Keyhanmanesh R, Aliparasti MR, Almasi S, Alipour MR. Effect of ghrelin on renal erythropoietin production in chronic hypoxic rats. Endocr Regul 48, 3-8, 2014.

Fry M, Ferguson AV. Ghrelin: central nervous system sites of action in regulation of energy balance. Int J Pept 2010, 2010.

Gasche Y, Copin JC, Sugawara T, Fujimura M, Chan PH. Matrix metalloproteinase inhibition prevents oxidative stress-associated blood-brain barrier disruption after transient focal cerebral ischemia. J Cereb Blood Flow Metab 21, 1393-1400, 2001.

Hossienzadeh F, Babri S, Alipour MR, Ebrahimi H, Mohaddes G. Effect of ghrelin on brain edema induced by acute and chronic systemic hypoxia. Neurosci Lett 534, 47-51, 2013.

Higashida T, Kreipke CW, Rafols JA, Peng C, Schafer S, Schafer P, Ding JY, Dornbos D 3rd, Li X, Guthikonda M, Rossi NF, Ding Y. The role of hypoxia-inducible factor-1 $\alpha$, aquaporin-4, and matrix metalloproteinase-9 in blood-brain barrier disruption and brain edema after traumatic brain injury. J Neurosurg 114, 92-101, 2011.

Huang CX, Yuan MJ, Huang H, Wu G, Liu Y, Yu SB, Li HT, Wang T. Ghrelin inhibits post-infarct myocardial remodeling and improves cardiac function through anti-inflammation effect. Peptides 30, 2286-2291, 2009.

Kheradmand A, Alirezaei M, Birjandi M. Ghrelin promotes antioxidant enzyme activity and reduces lipid peroxidation in the rat ovary. Regul Pept 162, 84-89, 2010.

Kojima M, Hosoda H, Date Y, Nakazato M, Matsuo H, Kangawa K. Ghrelin is a growth-hormone-releasing acylated peptide from stomach. Nature 402, 656-660, 1999.

Lee JY, Choi HY, Na WH, Ju BG, Yune TY. Ghrelin inhibits BSCB disruption/hemorrhage by attenuating MMP-9 and SUR1/TrpM4 expression and activation after spinal cord injury. Biochim Biophys Acta 1842, 2403-2412, 2014.

Liu Y, Wang PS, Xie D, Liu K, Chen L. Ghrelin reduces injury of hippocampal neurons in a rat model of cerebral ischemia/reperfusion. Chin J Physiol 49, 244-250, 2006.

Miao Y, Xia Q, Hou Z, Zheng Y, Pan H, Zhu S. Ghrelin protects cortical neuron against focal ischemia/reperfusion in rats. Biochem Biophys Res Commun 359, 795-800, 2007.

Mohaddes G, Abdolalizadeh J, Babri S, Abedini N, Hossienzadeh F. The anti-edematous effect of ghrelin in brain hypoxia is associated with decreasing expression of vascular endothelial growth factor. J Mol Neurosci 56, 273-277, 2015.

Mohaddes G, Abdolalizadeh J, Babri S, Hossienzadeh F. Ghrelin ameliorates blood-brain barrier disruption during systemic hypoxia. Exp Physiol 102, 376-382, 2017. 
Park SL, Won SY, Song JH, Kambe T, Nagao M, Kim WJ, Moona SK. EPO gene expression promotes proliferation, migration and invasion via the p38MAPK/AP-1/MMP-9 pathway by p21WAF1 expression in vascular smooth muscle cells. Cell Signal 27, 470-478, 2015.

Reszec J, Hermanowicz A, Rutkowski R, Turek G, Mariak Z, Chyczewski L. Expression of MMP-9 and VEGF in meningiomas and their correlation with peritumoral brain edema. Biomed Res Int 2015, 2015.

Rosenberg GA. Matrix metalloproteinases and their multiple roles in neurodegenerative diseases. Lancet Neurol 8, 205-216, 2009.

Sato T, Ito A, Ogata Y, Nagase H, Mori Y. Tumor necrosis factor alpha (TNFalpha) induces pro-matrix metalloproteinase 9 production in human uterine cervical fibroblasts but interleukin lalpha antagonizes the inductive effect of TNF alpha. FEBS Lett 392, 175-178, 1996.

Sifringer M, Genz K, Brait D, Brehmer F, Lober R, Weichelt U, Kaindl AM, Gerstner B, Felderhoff-Mueser U. Erythropoietin attenuates hyperoxia-induced cell death by modulation of inflammatory mediators and matrix metalloproteinases. Dev Neurosci 31, 394-402, 2009.

Vecil GG, Larsen PH, Corley SM, Herx LM, Besson A, Goodyer CG, Yong VW. Interleukin-1 is a key regulator of matrix metalloproteinase- 9 expression in human neurons in culture and following mouse brain trauma in vivo. J Neurosci Res 61, 212-224, 2000.

Wang H, Keiser JA. Vascular endothelial growth factor upregulates the expression of matrix metalloproteinases in vascular smooth muscle cells: role of flt-1. Circ Res 83, 832-840, 1998.Wang X, Jung J, Asahi M, Chwang W, Russo L, Moskowitz MA, Dixon CE, Fini ME, Lo EH. Effects of matrix metalloproteinase-9 gene knock-out on morphological and motor outcomes after traumatic brain injury. J Neurosci 20, 7037-7042, 2000.

Wu H, Dong G, Liu H, Xu B, Li D, Jing H. Erythropoietin attenuates ischemia-reperfusion induced lung injury by inhibiting tumor necrosis factor-alpha and matrix metalloproteinase-9 expression. Eur J Pharmacol 602, 406-412, 2009.

Yang Y, Estrada EY, Thompson JF, Liu W, Rosenberg GA. Matrix metalloproteinase-mediated disruption of tight junction proteins in cerebral vessels is reversed by synthetic matrix metalloproteinase inhibitor in focal ischemia in rat. J Cereb Blood Flow Metab 27, 697-709, 2007.

Zhang Q, Huang C, Meng B, Tang T, Shi Q, Yang H. Acute effect of ghrelin on ischemia/reperfusion injury in the rat spinal cord. Int J Mol Sci 13, 9864-9876, 2012.

Zigman JM, Jones JE, Lee CE, Saper CB, Elmquist JK. Expression of ghrelin receptor mRNA in the rat and the mouse brain. J Comp Neurol 494, 528-548, 2006. 